\title{
Creating entrepreneurial ecosystems for the reindustrialization of the Russian economy: the crisis impulse of 2020
}

\author{
Konstantin Yurchenko* \\ Ural State University of Economics, 620144, 8 Marta Str., 62, Ekaterinburg, Russia
}

\begin{abstract}
The global economy, which has been successfully developing for a long time under the influence of the globalization trend, experienced a serious external shock in 2020. The sharp halt in growth and the fall in GDP in most countries have led to the need to develop mechanisms for restoring growth, which are based on consumer and business activity. Russia has been hit by a double whammy of the crisis, as in addition to the decline in business activity, the impact of a decrease in demand for export commodities, while at the same time falling prices for them, affects. The article, based on fundamental and empirical works devoted to the study of business ecosystems and behaviors of a resource-dependent economies, the author, using techniques of statistical analysis substantiates opened for countries to undertake in the medium term reindustrialization of the economy, forming with the updated effective entrepreneurial ecosystem.
\end{abstract}

\section{Introduction}

The global economy, which has been under enormous pressure from the abrupt shutdown of business and manufacturing activity at the beginning of 2020 and is under the unrelenting impact of the economic consequences of the coronavirus crisis, is in search of optimal ways to restore economic growth. A lot of countries will end 2020 with negative GDP dynamics, while a return to growth next year is also not obvious. The extremely high level of uncertainty generated by the non-triviality of the current crisis and its global scale makes us look for unconventional ways out of this situation. Responding to the crisis, most countries almost immediately turned on standard anti-crisis mechanisms. However, traditional monetary stimulus through low interest rates and quantitative easing (QE) has shown little effectiveness, as is the case in deep shocks. And significant amounts of fiscal stimulus, implemented through large-scale subsidies to households and businesses, only partially supported aggregate demand, not keeping GDP from falling dramatically (for example, US GDP lost more than $31 \%$ in the Q2 of 2020). In addition, they have led to dramatic imbalances in financial markets and provoked a sharp increase in public debt, future payments on which will become a disincentive factor for economic growth in the future.

\footnotetext{
*Corresponding author: k.p.yurchenko@usue.ru
} 
Against the background of the world's leading countries, Russia is also experiencing problems with restoring economic growth. At the same time, given the resource-dependent economy, the crisis hit the country was particularly severe. A sharp decline in world energy prices and a significant decline in their export volumes due to a decrease in global demand from the stalled world economy make it impossible to continue operating the previous economic model, one of the key pillars of which were large vertically integrated oil and gas companies. Having demonstrated their lack of adaptability to the rapidly changing market environment, such companies were unable to become drivers of the post-crisis recovery, which prompted a new round in the search for a tools to exit the economy from a prolonged period of stagnation.

For the Russian economy, the severity of the current situation not only opens up opportunities for replacing the hypertrophied share of large companies with more mobile business structures. Dramatic events on the world oil market make it particularly relevant to question the country's economy's withdrawal from long-term resource dependence. Forecasts say that the period of low world oil prices will be long, so the Russian economy needs reindustrialization. Namely, in the crisis conditions, the scale of which is difficult to overestimate today, the launch of the reindustrialization program promises to bring the greatest results for the long-term development of the economy. Thus, in the next two or three years, the country will have to experience the reverse inertia of the "Dutch disease", in the inert wave of which economic regulators will try to form updated business ecosystems, creating the most favorable conditions for the economy to enter the long-term growth trajectory.

\section{Transformational dynamics ofentrepreneurial ecosystems and reverse dynamics of the "Dutch disease": empirical and applied aspects of research}

The multiplicity of vectors of development of a competitive economy has given rise to completely different forms of entrepreneurship: from small and medium-sized businesses, with which it is most often identified, to companies that grow into real giants of the industry and achieve huge capitalization (Amazon, Apple, Space-X, Tesla, and others), and even players who implement the practice of state entrepreneurship. At the same time, in countries where the tradition of state participation in the economy is strong, such as in Russia, small companies that participate on a par with state corporations in the competitive race become more efficient than the latter.

However, the development of free enterprise in the world's economic history is closely linked to building an institutional and market infrastructure that is friendly to economic growth achieved through the advanced development of the business sector. This approach is reflected in the concept of business ecosystems, including the entrepreneurial ecosystem. Back in the mid-1990s, James Moore formulated the concept of strategic planning of business ecosystems, as a set of own or partner services united around one company, pointing out that the state has a significant impact on the business ecosystem [1]. Moving on, J. Moore suggested that economic activity should be viewed as an ecosystem where buyers and producers play complementary roles, jointly evolving in the direction set by the companies at the center of the ecosystem. Thus, business ecosystems are an economic community that consists of a set of interconnected organizations and individuals. It creates products and services that are valuable to the consumer, which are also part of the ecosystem. The ecosystem of any enterprise also includes suppliers, leading manufacturers, competitors, and other stakeholders[2, 3]. Over time, they co-evolve their capabilities and roles and strive to match the directions set by leading companies that move the entire 
society towards a common vision. Developing this idea in the context of the most modern realities, R. Adner, M. Jacobides and others emphasize that business ecosystems describe schemes for launching entrepreneurial innovations and startups in general, which are extremely difficult to adapt to the environment and survive outside of the established ecosystem $[4,5,6]$. Thus, a well-formed business ecosystem becomes fundamentally important for the successful development of entrepreneurship, which outside of it is doomed to quite large losses at the start-up stage, which reduces entrepreneurial activity and creates a lag in the economy [7].

The entrepreneurial landscape of the Russian economy, which had barely begun to be defined in the course of grandiose transformational reforms in the early 1990s, was largely distorted by the consequences of the "Dutch disease"acquired by the country. Despite the fact that the emerging resource dependence did not manifest itself too significantly in the Soviet planned economy, the consequences of the fall in oil prices in the 1990 s were very severe, although they were veiled by transformational shocks. And so, with the advent of the era of oil abundance in the 2000s, the "Dutch disease" of the Russian economy declared itself in full force, giving rise to traditional consequences for the business landscape. Russia has consistently passed the stages of increasing export raw material revenues, increasing imports of tradable goods while reducing their production on its territory, and increasing the supply of non-tradable goods, which became a classic manifestation of the "Dutch disease" described by M. Corden [8]. Moreover, the country began to experience the influence of a broader phenomenon - the resource curse, the characteristic features of which R. Auty identified lower growth rates and lower institutional quality of the economy, and $\mathrm{H}$. Mehlum modeled social dynamics in detail with the connivance of the practice of institution-building $[9,10]$. As a result, the Russian economy was largely deindustrialized and vulnerable to the risks of a sharp negative adjustment in the price environment of energy markets. The reaction of the established structure of the Russian economy resulted in the consequences of global changes in the world economy in the first and second quarters of 2020, shown in Figure 1.

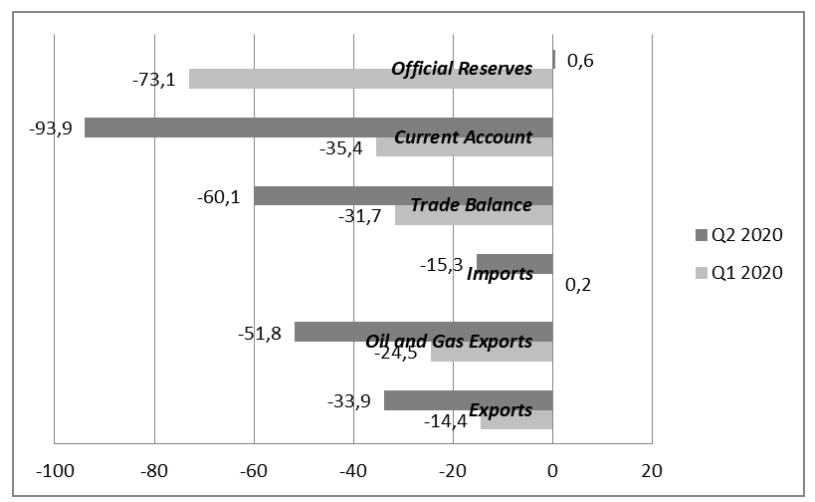

Fig. 1. Percentage change in some indicators of the Russian foreign trade sector in the Q1 and Q2 2020 compared to the same indicators of the Q1 and Q2 2019 (Bank of Russia)

In their recent work, G. Toews, T. Harding and R. Stefanski used a large sample of past energy price shocks to identify quantitative changes in the relative prices of tradable and non-tradable goods, and also estimated the extent of labor redistribution caused by the "Dutch disease" between the relevant sectors [11]. From this and a number of other works, it can be assumed that the mechanism that stimulates the growth of the traded sector after the cooling of the global resource markets is largely a mirror image of the "Dutch disease". Accordingly, if one of the most significant consequences of the "Dutch disease" is the deindustrialization of the economy, then the macroeconomic consequence of the reverse 
process may be its reindustrialization. And the events that we will observe in the world economy in the next two years will become the empirical basis that is designed to confirm this hypothesis. Of course, the situation will vary by country. It is obvious that the Russian economy, for example, will be easier to reindustrialize, starting from its own structure 30 years ago.

As M. Corden noted in his research, during high oil prices, a growing society increased its consumption of both tradable and non-tradable goods. The growing demand for tradable goods was offset by an increase in their imports. Competition between suppliers of imported goods makes it possible to manage with low prices, which, moreover, do not grow due to the strengthening of the national currency. And the growing demand for non-tradable goods does not always meet the relevant increase in their supply, which pushes their prices up. Profitability in the non-tradable sector increases along with the salaries of employees employed in it, which encourages the flow of labor into it $[12,13]$. This is the logic of the "Dutch disease". During periods of persistently low oil prices, it is reasonable to expect the opposite changes.

\section{Reflexive interaction between the formation of entrepreneurial ecosystems and the reverse inertia of the "Dutch disease" in Russia in the Wake of the coronavirus crisis}

So, the Russian economy is clearly in need of reindustrialization not only to create a Foundation for recovery from the crisis that occurred in 2020, but also to support long-term economic growth in the future. A return to the growth model that a resource-dependent economy could implement is highly unlikely, so structural changes in the economy are inevitable. However, as history has shown, these changes are more steadily and successfully generated by a mobile business environment than by large state-owned companies and corporations with a high degree of monopoly power in the market. This means that the country is facing the need to create updated business ecosystems, and in this process we will have to restart the procedures for interaction between business, the market and the state, while significantly updating the business landscape.

Entrepreneurial ecosystems fill not only the business and institutional space of the country's economy, but also acquire a global character, becoming in fact an institutionalized representation of specific niches occupied by entrepreneurs, mastering which the relevant businesses become active in developing mutually beneficial relationships with their customers, suppliers, competitors and the state. Based on the General logic of the gradual rise in the cost of entrepreneurial startups caused by technological requirements and increased security requirements, Russian entrepreneurship needs not just state support for small business development, but the formation of a built-up ecosystem that actively promotes the growth of entrepreneurship. At the same time, banks, venture funds, universities, and the state fall into the orbit of the entrepreneurial ecosystem, forming its structure. Of course, this does not exclude the existence of state-owned enterprises of an entrepreneurial type, but it implies a gradual rejection of existing state corporations. Experience has shown that their mistakes are too frequent and their ecosystems are so vast that any such mistake is too costly for a large part of the economy. Formed effective and sustainable business ecosystems will allow you to develop a more productive set of processes for developing and commercializing new ideas, allowing you to generate them faster, shorten the cycle of launching startups for sale and get access to optimal financing schemes. And the development of the modern economy allows us to speak not only about the formation of independent ecosystems of individual businesses, but also about their interconnectedness, as well as about the gradual formation of a global business ecosystem 
based on interstate agreements and mechanisms that ensure their implementation. Thus, entrepreneurial activity fits perfectly into the business environment, forcing the authorities to constantly improve the institutional architecture of the economy as a whole, balancing the interests of different economic entities and generating economic diversity, which has a positive impact on the growth of public welfare.

Russian business, which experienced the crises of 1998, 2008-2009, and 2014-2015, faced an unprecedented threat of closure in 2020. The entrepreneurial ecosystems of many Russian small businesses, if not destroyed, then at least forced to undergo a radical transformation. And the state can play a significant role in this crisis transformation of ecosystems. Today's problems are not caused by conditions, institutions, or organizational suboptimality. The root cause is a drop in demand, which has created a shock in the business ecosystems that have been built for so long. And in them, all the elements are interconnected, so the shock that has arisen in the ecosystem does not disappear, reflexively reflecting on the position of all its elements, in the event of a crash generates a "Domino effect", and therefore requires a reconfiguration of the entire system to extinguish it. The danger is that supply chains established between companies can break down unpredictably due to sharp cost reductions in various market segments, as well as, as practice has shown, due to asymmetric forced closure during epidemics. Only the fastest possible recovery in demand will solve the problems that companies have encountered and restore their ecosystems, which will take time. Until then, direct state support is needed to stabilize the situation. Business ecosystems themselves, which have been unbalanced by the crisis, are in a state of flux when changes are most productive.

Such changes can be the creation of a flexible system of anti-crisis economic support for citizens and small businesses, leading to a rapid exhaustion of the depth of financial losses during the crisis and reducing the level of uncertainty. In addition, the formation of updated business ecosystems should occur against the background of the final acceptance by the state of the status of" payer of last resort", which private companies can not act in principle. The key task of the authorities is to move away from manual management procedures with temporary emergency support measures and create opportunities for creating effective selfadjusting business ecosystems. At the same time, realizing that the latter will happen the sooner, the faster market demand will recover, the focus of anti-crisis programs should be on subsidizing final consumption of households.

Implementation by the economic authorities of a comprehensive approach to anti-crisis support of the economy, applying a wide range of monetary measures (through lowering interest rates and injecting additional liquidity) and fiscal policy (through subsidizing households and companies). This is why we can talk about creating a new business landscape and renewing ecosystems. The new formats of interaction with business created with the active participation of the authorities have already begun to influence the renewal of business ecosystems, which will allow companies to adapt to the changed situation and regroup their resources. At the same time, it is no accident that in the conditions of global uncertainty, when entrepreneurs have not yet developed new ideas, the state becomes the initiator of changes.

The current state of the Russian economy allows us to see a reserve for a significant strengthening of the business sector in a fairly significant share of imports in consumption and the formation of export competitive advantages. To implement the latter, reindustrialization is necessary, which will quickly overcome the stage of import substitution and immediately move to export substitution of raw currency earnings by domestic household expenditures. At the same time, financial support for the latter by the state can accelerate the process of economic transformation. And the fall in global oil prices makes such a program all the more likely. Figures 2 and 3 show how Russian small and 
medium-sized businesses react to changes in the exchange rate, as well as the positive reaction of the latter to changes in the share of imports in consumption.

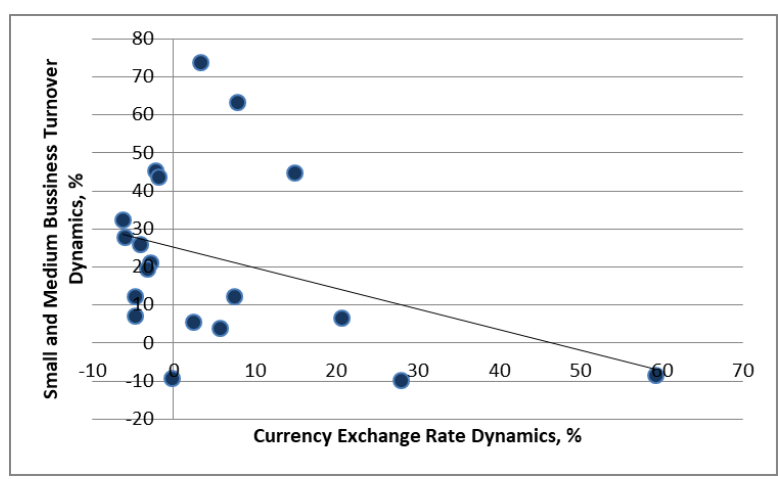

Fig. 2.Impact of exchange rate changes on the turnover of small and medium-sized businesses in 1998-2019 (Bank of Russia, Rosstat, GEM)

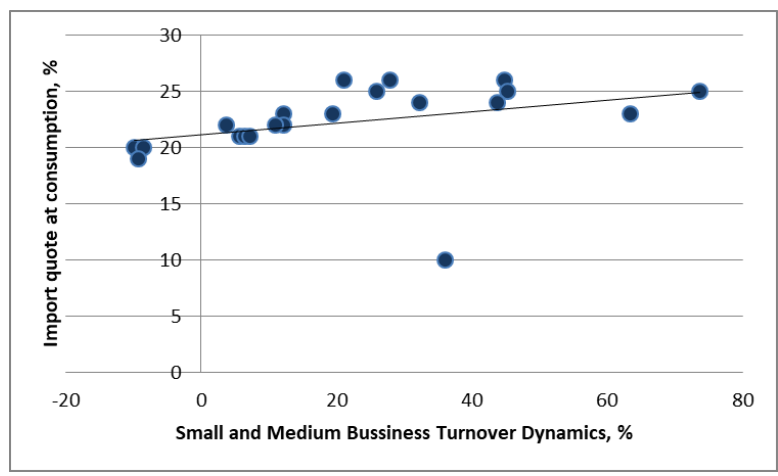

Fig. 3. Correlation of changes in the share of imports in consumption and turnover of small and medium-sized businesses in 1998-2019 (Rosstat, GEM)

Researchers have repeatedly shown that commodity price cycles play an important role in changes in relative prices and, as a result, can be used to select the moment when the strategy of reindustrialization of the national economy begins [14]. Just as during the" Dutch disease", the systematic strengthening of the exchange rate forced the economy to curtail its own processing production, so during the fall of the exchange rate, this production will recover. Moreover, if the strengthening of the exchange rate and the curtailment of production are always slow processes, then the collapse of the exchange rate can be quite sharp, which instantly creates the necessary incentives for import substitution and reindustrialization. Empirical estimates of Toews, Harding and Stefanskyshow quite significant strengthening of the growth potential of the resource sector arising from new discoveries or because of a rise in oil prices on the world market and a noticeable decline in employment in the tradable sector.

If we assume that the global economy, like most countries individually, behaves symmetrically during boom and bust periods, we can predict that if we lose part of our GDP due to a drop in income from commodity exports, we may see a proportional drop in prices for non-tradable goods and an increase in employment in the tradable sector. Given that over a sustained period of strengthening of the ruble in the period 2000-2008 rate strengthened by $14 \%$, and the price of the traded good over the same period, increased our estimates by $160 \%$, and the non-tradable to $548 \%$, based on the assumption of a symmetric reaction, we can assume that is real comparable depreciation of the ruble in the short term 
can stimulate the lower prices for non-tradable goods, at least twice, especially amid falling solvency of the population.

Instead of imported goods that have become unaffordable, demand will begin to switch to their domestic counterparts. Our economy experienced a very similar process from the end of 1998 to 2002. Despite some losses in the quality characteristics of consumption, this process should be considered positive for society. Mobile entrepreneurs, as our experience of twenty years ago has shown, are able to quickly establish the production of consumer goods instead of imported ones and, thereby, create new business ecosystems with new supply chains and distribution of manufactured goods. Employment in the manufacturing sector, as well as in trade, will inevitably begin to grow, and entrepreneurs will give the economy a chance to get out of the crisis, and even with an updated structure in favor of the new industrialization. Today, it is essential for the state to participate in the creation of updated business ecosystems, which was noted above.

Thus, the Russian economy, based on its historically created production capabilities and pushed by the current global economic crisis, is able to implement a reindustrialization strategy that can not only radically update its industry structure within a few years, but also create updated effective business ecosystems that ensure stable growth of public welfare.

\section{Conclusion}

The analysis allows us to conclude that there is a high probability of changes in the structure and format of the functioning of the Russian economy in the medium term. Structural changes will inevitably lead to changes in the business landscape in the country. This will change not only the industry structure of the business that adapts to changing consumer preferences, but also the ownership structure and size of companies. Objective crisis difficulties will lead to a wave of mergers and acquisitions, as a result of which the remaining companies on the market will become, on average, larger, freeing up niches for the emergence of completely new entrepreneurial businesses, while corporations that occupy a monopoly position in the markets will be enlarged.

The collapse of prices on the world oil market in the spring of 2020, which quickly manifested itself in a drop in export revenues, as already noted above, can launch a long term structural process that can change the economy of resource-dependent countries-a kind of reverse of the "Dutch disease". And the opportunities that open up for the Russian economy in this regard look very promising, given that the country's economy has recently been quite diversified in its structure by historical standards. And a number of features of the reaction and the relationship of economic indicators can contribute to the rapid transition to growth. And ensuring its rapid recovery will be the cornerstone of structural industrial policy in the medium term. A long-term steady decline in income from commodity exports will not only lead to the depreciation of the national currency, but through a decrease in real disposable income in the first phase, caused by the depreciation of the ruble and the large share of imports achieved in consumption, will cause a forced reduction in previously inflated prices of non-tradable goods (including services), reducing demand for them. At the same time, the parallel rise in the price of traded goods of imported production due to the transfer of the effect of exchange rate changes to them will begin to stimulate active import substitution in this sector. All this will lead to a decrease in the number of people employed in the service sector and to an increase in employment in the manufacturing sector. This is not an ideal dynamic, but it is a real way to return to a diversified economy with high rates of economic growth.

Like any major crisis, the events of 2020 will generate new growth points. And the first who will start to develop their potential will not be state-owned companies, but entrepreneurs. The task of the state at this stage is to support. After all, we are talking about 
a real opportunity to reindustrialize the Russian economy, using the inertia of the macrodynamics of the current crisis. Today, the global energy market environment, the mechanism for linking the Russian currency market with it, and promising opportunities for updating business ecosystems create favorable conditions for this.

\section{References}

1. J. Moore, The Death of Competition, 11 (1996)

2. Z. Acs, E. Stam, D. Audretsch, A. O’Connor, Small Bus. Economics, 7 (2017)

3. Y.D. Burda, I.O. Volkova, E.V. Gavrikova, Russian J. of Management, 84 (2020)

4. R. Adner, J. of Management, 51 (2017)

5. D. Audretsch, M. Belitski, J. of Technology Transfer, 42(2017)

6. M. Jacobides, C. Cennamo, A. Gawer, Strategic Management J., 29 (2018)

7. B. Spigel, Entrepreneurship Theory and Practice, 52 (2017)

8. W. M. Corden, J.P. Neary, The Economic J., 14 (1982)

9. R. M. Auty, Resource Abundance and Econ. Development, 33 (2001)

10. H. Mehlum, K. Moene, R. Torvik, The Economic J., 58 (2006)

11. G. Toews, T. Harding, R. Stefanski, The Economic J., 16 (2020)

12. H. Bjornland, L. Thorsrud, The Economic J., 28(2016)

13. M.L. Ross, Annual Review of Political Sci., 17 (2015)

14. A.J. Venables, J. of Econ. Perspectives, 15 (2016) 